\title{
Designing and Upgrading the Assembly Process and Verifying the Performance of the Pick to Light System Program
}

\author{
Naqib Daneshjo', Albert Mareš², Erika Dudaš Pajerská', Zuzana Hajduová' \\ 1 Faculty of Business Economics with seat in Kosice, University of Economics in Bratislava, Tajovského 13, 04 \\ 130, Košice, Slovakia \\ 2 Faculty of Mechanical Engineering, Technical University of Kosice, Letna 19, 040 01, Kosice, Slovakia \\ * Corresponding author's e-mail: daneshjo47@gmail.com
}

\begin{abstract}
The aim of the work is to change the current program in the programmable logic controller (PLC) to be as close as possible to the real-world Pick to Light system in the automotive industry for installing individual car components. The change consists in completing the navigation and tutorial mode while preserving the original function of the program, which is to measure the time of each step in assembly of the components and the reading of the pieces from the trays. A simple virtual laboratory model was created which enables to test the program even if the access to the PLC and HMI panel is not possible. The partial goal was to modify the visualization of the program in the operator touch panel Human - Machine Interface (HMI). Another partial goal was to implement a new PLC program. In order to better understand the created program, the flowcharts were created and described for the main parts of the program.
\end{abstract}

Keywords: PLC system, automotive industry, pick to light system, HMI panel

\section{INTRODUCTION}

At present, the topic of cost savings is very relevant. In automotive production, repair of faults and the production of non-distributors are very expensive. Therefore, more and more systems are being used to prevent the production of non-products, faulty products and, in particular, to detect errors directly at their source. One of these systems is also the Pick to Light system which has a wide application in manufacturing, assembly and logistics.

The work is devoted to PLC automation programming. The principle of PLC automation is explained and a simple example describes the program writing methodology. The work also contains a detailed procedure for backing up and recording the program into the PLC which allows the program to continue working, editing and testing. The paper briefly describes the programs needed to edit the program in the PLC, the HMI panel screen and a virtual model of the Lean Laboratory which allows the program to be tested without connecting to the PLC or HMI panel itself.

Lean Manufacturing is a systematic approach to identifying and preventing wastage (limiting the performance of value-added activities) by continually improving the production processes. Systematically eliminating sources of waste reduces the production costs. At the same time, it is necessary to remember the customer requirements and also to increase the added value of the production process.

However, in some cases, the customer's requirements necessitate certain wastage which should be highlighted and the excess costs associated with this waste may be taken into account in the end product price.

Waste is the opposite of added value. This statement includes all the activities that the customer does not want and will not pay for. For example, the customer is willing to pay for sheet metal, sheet metal bending, welding, surface treatment, and so. However, he is not willing to pay for waiting time, repairs, surplus stocks, and so on. 


\section{DESIGNING THE PICK TO LIGHT SYSTEM PROGRAM}

Programmable automaton (PLC) is the most used automation tool in industry. The automation technology has been in use for about 30 years. Programmability close to the mentality of the designer is its typical feature. Originally, the PLC was designed for machine control as a substitute for fixed relay logic. This also corresponds to the programming language of the contact (relay) schemes.

\section{Programming of PLC}

The languages of the first PLCs had several commands (typically 8 or 16) that were equivalent to switching and expanding contact, parallel and serial rack, coils, memory circuits, counters, and timers. Today, there are several types of languages available for each programmable machine: except the language of the contact schema, it is the language of logic schemes, the mnemocode language or other textual language and also the language of sequential programming. Contemporary programming languages are considerably richer; unfortunately, the mentality of designers and constructers has come to a halt, so that a "PLC programmer" has become a separate profession. Unification of programming languages and development systems for PLC is the goal of the new international standard IEC 61131-3.

Programmability and versatility of construction provide the PLC with their versatility and adaptability. It is no longer true that the PLC only solved logical tasks, while specialized controllers were used to process analog variables. PLC today can handle both types of tasks (and many more). The PLC program can make connections and treat logical connections that are unavailable while using specialized and closed devices. For example, it is possible to solve the links between regulating different variables (for example temperature and humidity, temperature and burning quality, temperature and compliance) or optimize the process and adapt it to changing conditions, as well as minimize consumption, costs, or losses.

In order to meet the additional requirements, the unchanged PLC configuration is met many times, and increased costs are "only" in programming, creating and validating the program (PLC is "software" but it is definitely not free). Numerous new features are only implemented during operations, based on additional user requirements (sometimes they know what is really needed when they are in operation, sometimes they are forced by a change in technology or a changed situation for the user).

It is customary that - in addition to their own control functions - the PLC system is entrusted with analytical functions (error and risk recognition, energy and raw material analysis, production tracking, non-production, loss and deterioration, waste and waste assessment, performance monitoring and staffing); protection and controls (from unsafe or unwarranted operation of the operator, from any threatening loss or accident). It is clear from the above that today the knowledge on PLC programming is a major advantage for a technician working in the automation industry.

\section{Characteristics of the development environment for programming of PLC}

With CX-One software one can build, configure and program networks, programmable terminals, PLCs, drives, temperature controllers, sensors and motion control systems. The CX-One environment is based on the application software components such as CX-programmer, CX-designer network manager, CX-integrator and CXserver, acting as network-based software applications and application software.

The advantage of such architecture is that users do not have to worry about networks or device drivers while developing their applications. The CX server supports all Omron networks and Omron operating systems.

The disadvantage of this software is the fact that the CX-One is paid. This indicates that Omron PLCs are designed for industrial use and not for an individual or small business.

CX- One includes these programs:

Programming:

- CX- Programmer - PLC automation programming

- CX-Simulator - simulation of automata PLC

- CX- Designer - programming of control terminals

Drives and motion control:

- CX-Motion - for motion control units with analog output

- CX-Position - for PTP motion controls with impulse output

- CX-Motion - NCF - for PTP motion controls with MechatroLinkII 
- $\mathrm{CX}$ - Motion - MCH - for advanced PTP motion controls with MechatroLinkII

- CX- Drive - for inverters and servo drives

Regulation and switching:

- CX- Process Tool - for PLC process units

- CX-Thermotools - for separate temperature controllers

Networks:

- CX- Integrator - industrial networks DeviceNet, Ethernet, Controllerlink, NT-Link, Compoway/F

- CX-Profibus - all Profibus modules [12]

PLC programming was linked to the CX-One software packages from CX-programmer, which allows advanced and complex programming. Programming environment CX-programmer is used for programming and subsequent program recording in PLC.

The program can be designed using the following programming languages:

- Programming using ladder diagrams LD

- Programming using structured text language ST

The Ladder Diagram (LD) is the most common way of PLC programming by drawing schematics using symbols representing contacts, outputs, wires and a large number of instructions. Each management application written in the CX-Programmer development environment is run as a project. The project may contain several tasks.

There are two types of tasks: cyclical and interrupting. A cyclic task is executed after running in each PLC cycle until it is paused. One cycle of the interrupting task is always executed by interrupting the program to which the assignment is assigned. After it is run, the job stops, the interruption terminates and the program runs cyclically. For easier orientation in a large program, tasks can be further subdivided into arbitrary sections with a freely definable name. The section is as a chapter in the book, and the PLC goes through the sections in the order they are defined in. The sections can be simply reengineered and copied freely in the program. Each section consists of any number of so-called rungs. It is actually a program line that must always contain at least one contact and at least one output or output instruction.

CX-Programmer programming environment also has the so-called functional blocks - FB. These are predefined programs or features dis- played as a simple program element containing inputs and outputs. The function block can be defined by LD or ST. FB contains inside the definition of variables and the program itself. One already created function block can be used repeatedly in the form of instances. The user just defines the inputs and outputs. Each instance of FB uses its own allocated memory for its function. FB can be saved in a library and used in another application. This saves the programmer's work and scans the written program.

\section{USING OF PROGRAM}

The use of the new program is partly explained in the description of the algorithms. However, it is based on the assumption that the user was working with the original program. This manual also describes the operator for noninterested users.

After the PLC is turned on and the program is loaded, the screen shown in Figure 1 is displayed. The "learn cycle" message is displayed. The "two hands" message is not displayed and the STOP LEARNING button is also not displayed. Sensors, time measurement, countdown and STOP NAVIGATION, START NAVIGATION buttons are inactive.

Currently, we can vary the amounts in each field, the minimum quantity limit or press the RESTART and START LEARNING buttons. Pressing the START LEARNING button activates the sensors. We gradually put our hand into the individual trays. Step saving is indicated by the sensor light. The maximum number of steps learned is nine, the minimum is three steps. After learning three or more steps, the "learn cycle" message disappears.

If the required cycle is learned, STOP LEARNING button can be activated. The START NAVIGATION button is activated to initiate navigation. When the button is pressed, the sensor lights up above the appropriate tray where we put our hand in the first step. The program will run continuously until we press the STOP NAVIGATION button. After pushing the button, we need to complete the cycle until the timer is switched off, read from the trays and the table data is stored on the USB key when connected to the HMI panel. Now, one can start navigating the same cycle again or learn the new cycle by pressing the START LEARNING button. 


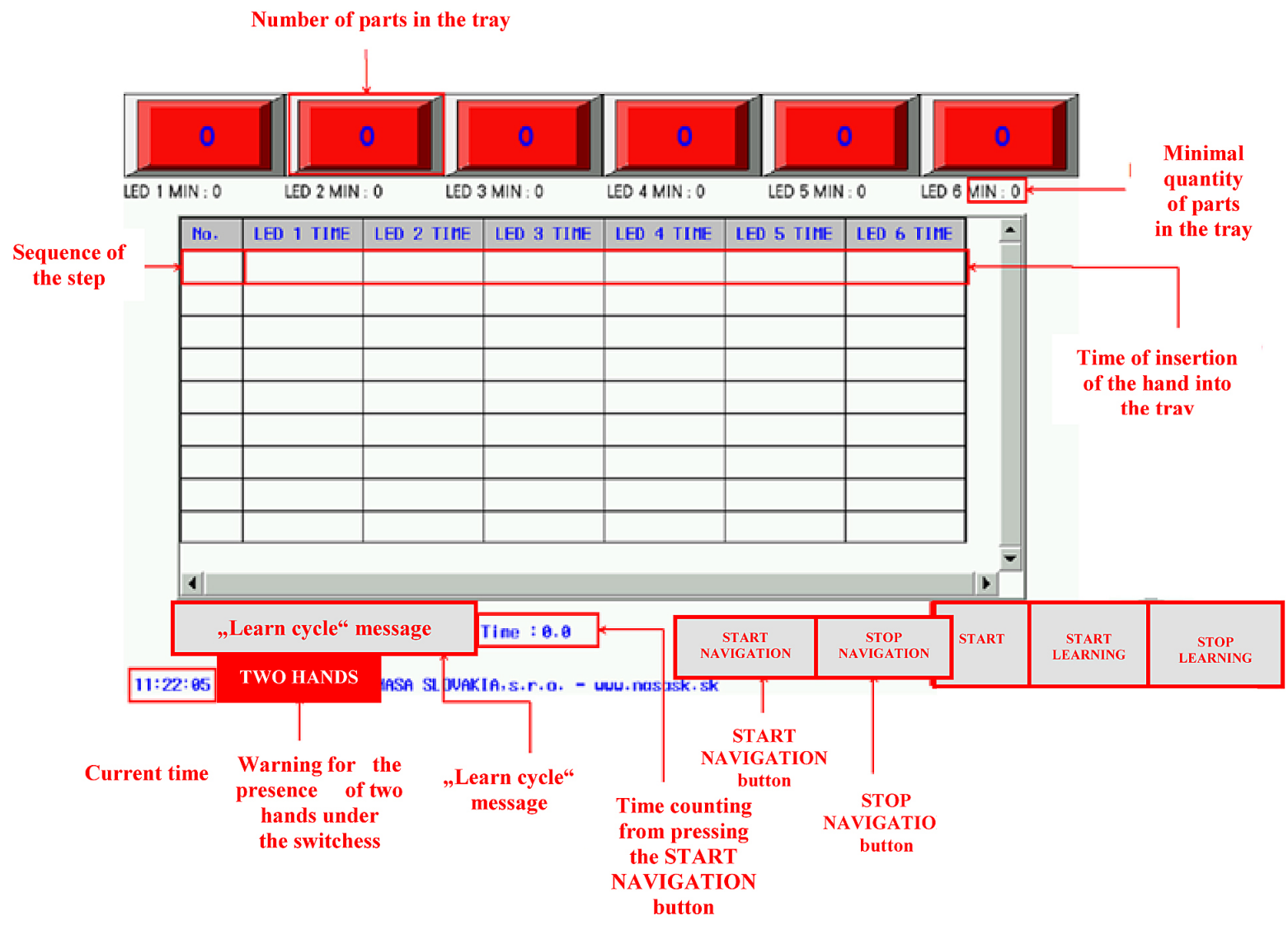

Fig. 1. HMI Display used with new program

Functions of individual elements / buttons:

- 6 red squares - represent the trays under the sensors, it is possible to edit the number of pieces after clicking on them,

- LED x MIN - limit of the minimum number of parts in the tray, it can be changed at any time,

- Table - times of inserting a hand into individual trays are written and the total sequence of the step for the entire time of the navigation that is being launched, cannot be edited,

- Current time - displays current time, cannot be edited,

- "Learn cycle" message - displayed if the number of stored steps in the PLC is less than 3 , cannot be edited,

- Warning „Two hands“ - will appear if two hands are put under two different sensors during navigation, cannot be edited,

- Time - displays the time counting from pressing the START NAVIGATION button until the cycle stops, cannot be edited,

- START NAVIGATION - the start button for navigation is only active if three or more steps are stored and the learning mode is not running at the same time,
- STOP NAVIGATION - stop button for navigation, active if the learning mode is not running,

- RESTART - deleting table data, does not delete the sequence learned from PLC, it must be kept for more than a second for security reasons,

- START LEARNING / STOP LEARNING the START LEARNING button is used to start the learning mode, after it is pressed to change to the STOP LEARNING button which ends the learned cycle, the buttons are inactive when the navigation is started.

\section{DESIGNING THE ASSEMBLY PROCESS AND VERIFYING THE PROGRAM OPERATION}

The pre-assembled product is the rear door lock of the Volkswagen Group (Golf 4, Octavia 1, Audi A3, Passat B5). The lock is used to lock the door in the closed position. The lock also includes central locking electronics. It consists of two main parts: electronic and mechanical. 
Thanks to this connection, the control unit can accurately determine in which position the lock is currently located. It can evaluate whether the door is closed and if it is closed properly. The lock has a SAFE locking function; it means that cannot be opened from the exterior but not using the inside door handle.

Figure 2 illustrates a door lock fitted by us. Figure 3 shows a view of a door panel installed in the door. The door lock is not visible from this point of view either. Attaching the lock to the door panel and the lock itself is only visible after removing the door panel on the rear panel.

The door lock with marked individual components can be seen in Figure 4. At first glance, the simple component consists of twenty types of components and twenty-five elements. Decomposition of the product is shown in Table 1

\section{Technological process of assembly}

Figure 5 and Figure 6 present the graphs showing the sequence of the door lock assembly. Since the lock consists of twenty kinds of components but the lab has six sensors, we have tried to select from each operation one component that will be placed under the sensor.

The part located in the container placed under the sensor is in the green ring. In the first operation Insertion 1, it is for example component S20 - front cover. The criterion for selecting this component was to be the basic component from the ones assembled in the operation. The last operation Insertion 4 is exception because it takes only a few seconds, and therefore we can determine the end of assembly of the product according to this part.

Figure 7 is a lay-out of the workplace on which the individual components are placed in

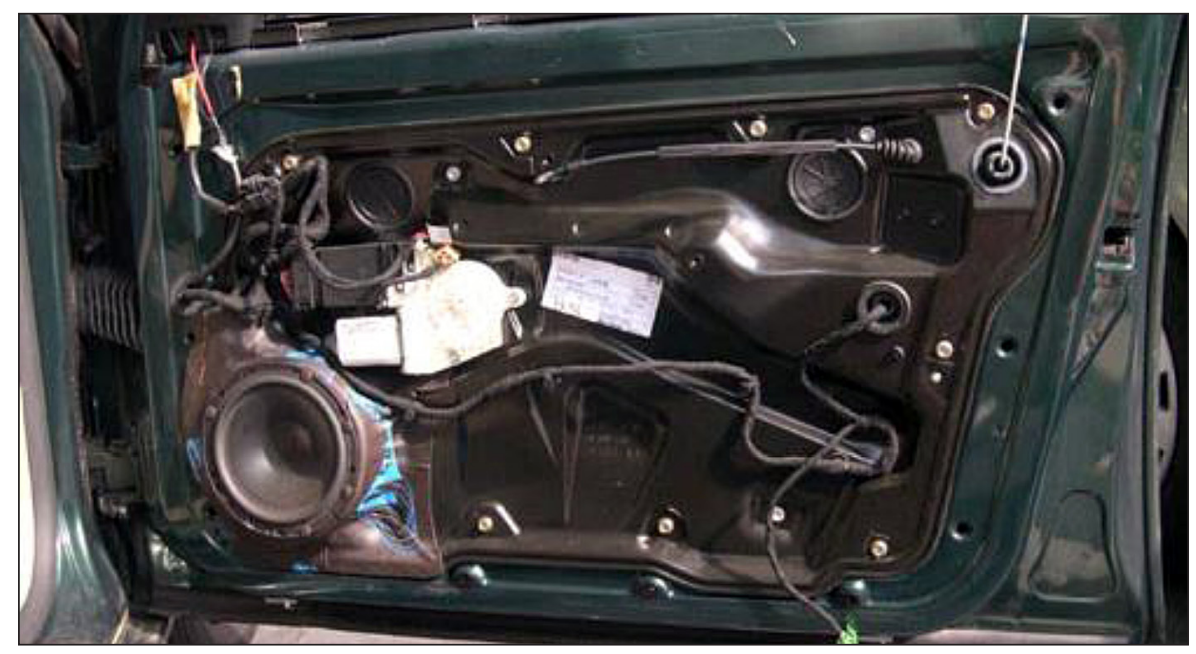

Fig. 2. View of the door panel

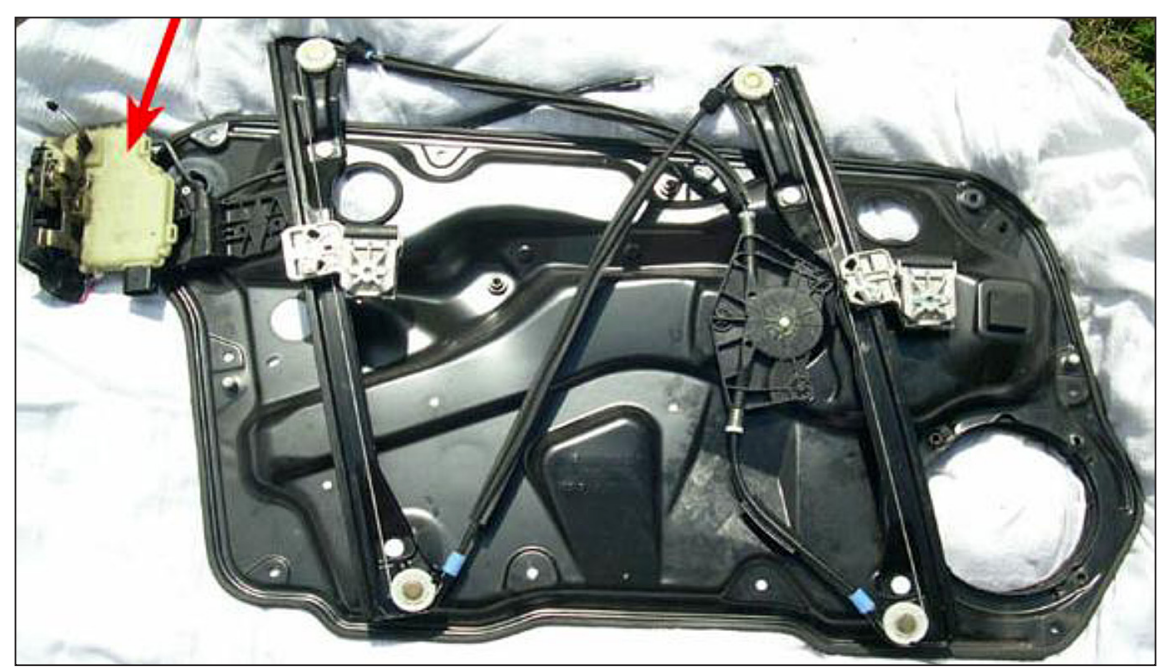

Fig. 3. View of the lock installed on the door panel 


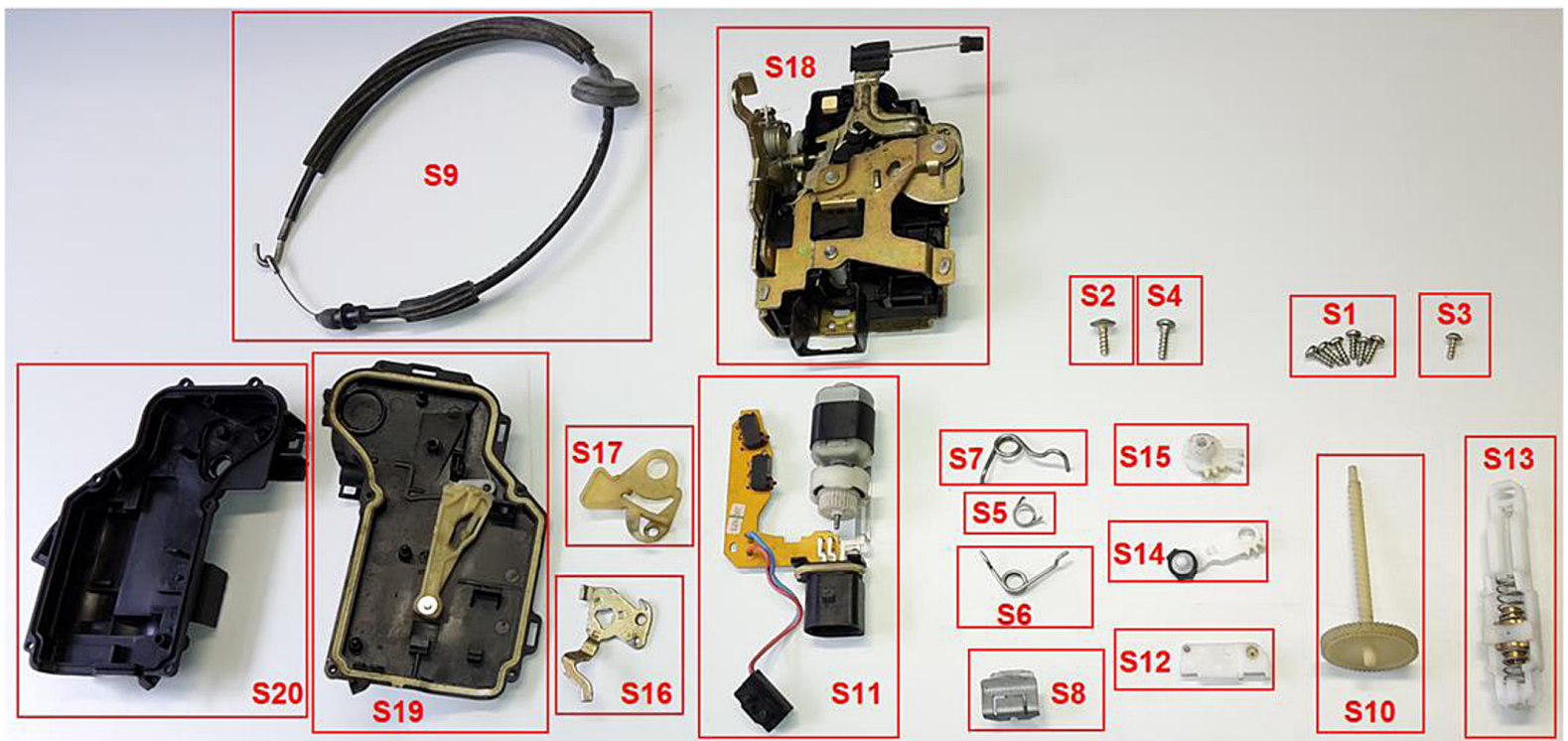

Fig. 4. Decomposition of door lock with marked parts

Table 1. Decomposition of the product

\begin{tabular}{|c|c|c|c|c|c|}
\hline & Title & Number of pieces & & Title & Number of pieces \\
\hline S1 & Screw in plastic $3 \times 9$ & 6 & S11 & Circuit board with motorcycle & 1 \\
\hline S2 & Screw in plastic $4 \times 13$ & 1 & S12 & Connection of the motor & 1 \\
\hline S3 & Screw in plastic $3 \times 7$ & 1 & S13 & Shaft mechanism & 1 \\
\hline S4 & Screw in plastic $4 \times 12$ & 1 & S14 & Motor arm & 1 \\
\hline S5 & Spring „a“ & 1 & S15 & Wheel of motor arm & 1 \\
\hline S6 & Spring „b“ & 1 & S16 & Metal molding & 1 \\
\hline S7 & Spring "C" & 1 & S17 & Plastic molding & 1 \\
\hline S8 & Microswitch clip & 1 & S18 & Lock & 1 \\
\hline s9 & Cord handle rod & 1 & S19 & Back cover & 1 \\
\hline $\mathrm{S} 10$ & Plastic shaft & 1 & S20 & Front cover & 1 \\
\hline \multicolumn{2}{|r|}{ Total } & 15 & \multicolumn{2}{|r|}{ Total } & 10 \\
\hline
\end{tabular}

the containers. In this figure, we may notice the layout of the workspace from the perspective of the operator. In the upper part of the left is a finished lock and the lock on the right is divided into individual parts.

\section{Realization of assembly with a new program}

While installing a lock with a new program, the work layout does not change; it remains the same as in the Figure 8. We can note that thirty seconds have elapsed since the navigation was started until the removal of the component from the cartridge under the number one sensor. The reason for this time difference was the demonstration of the program's resistance to the mistake of inserting the hand into the wrong stack. Even though the hand was intentionally inserted into the wrong tray, the program did not write the time of the wrong step. Thus, if we were about twenty- eight seconds off each step (because otherwise it takes about two seconds to remove the first part) we would obtain approximately the same time of assembly of the entire lock. The reason why the times are basically the same is the fact that the lock is made up of twenty components and the sensors are available at six. In this case, the benefit of the new system has not been proven in the shorter time. However, it is fault-tolerant, making it easier to analyze the output data.

The new program is much closer to the principles of Pick to Light. It can, similarly to the original program, measure the pitch times and subtract from the number of pieces in the individual bins. At the same time, however, the system can learn its own cycle that will be navigated by the operator when installing the component. Even bugs such as inserting both hands into different trays and inserting a hand into the wrong tray are treated in the program. 


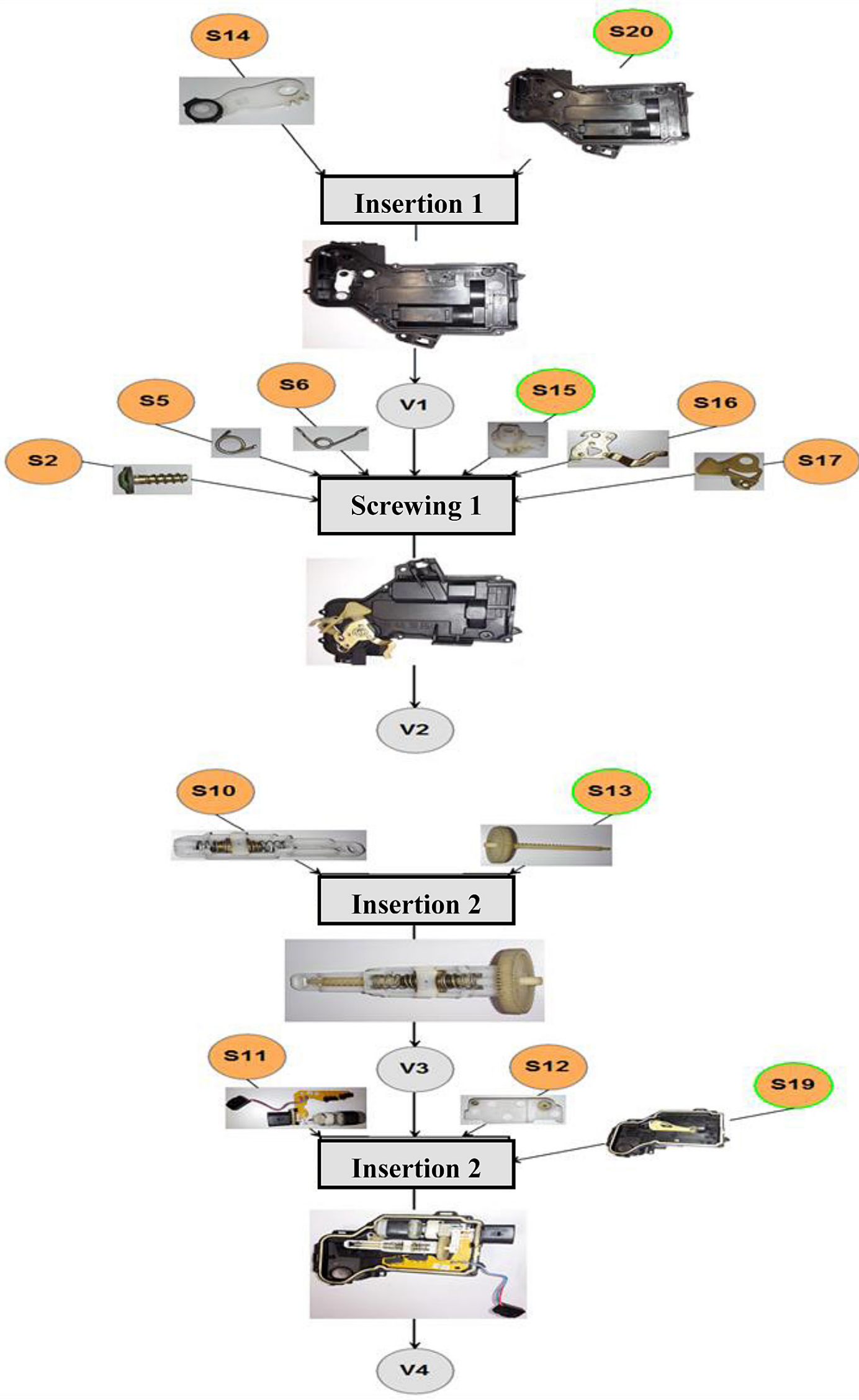

Fig. 5. Step diagram of installing the lock - first part 


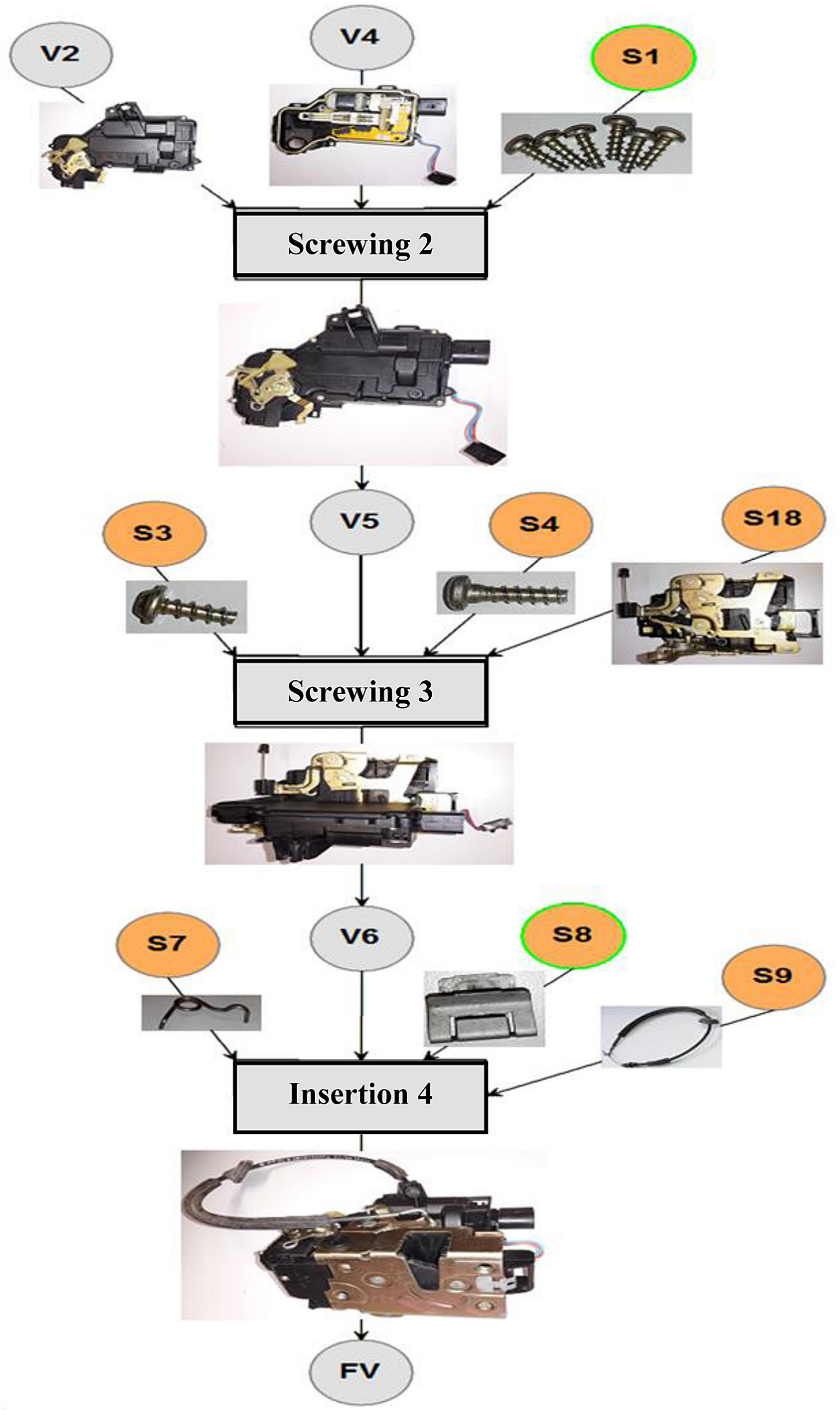

Fig. 6. Step diagram of installing the lock - second part 


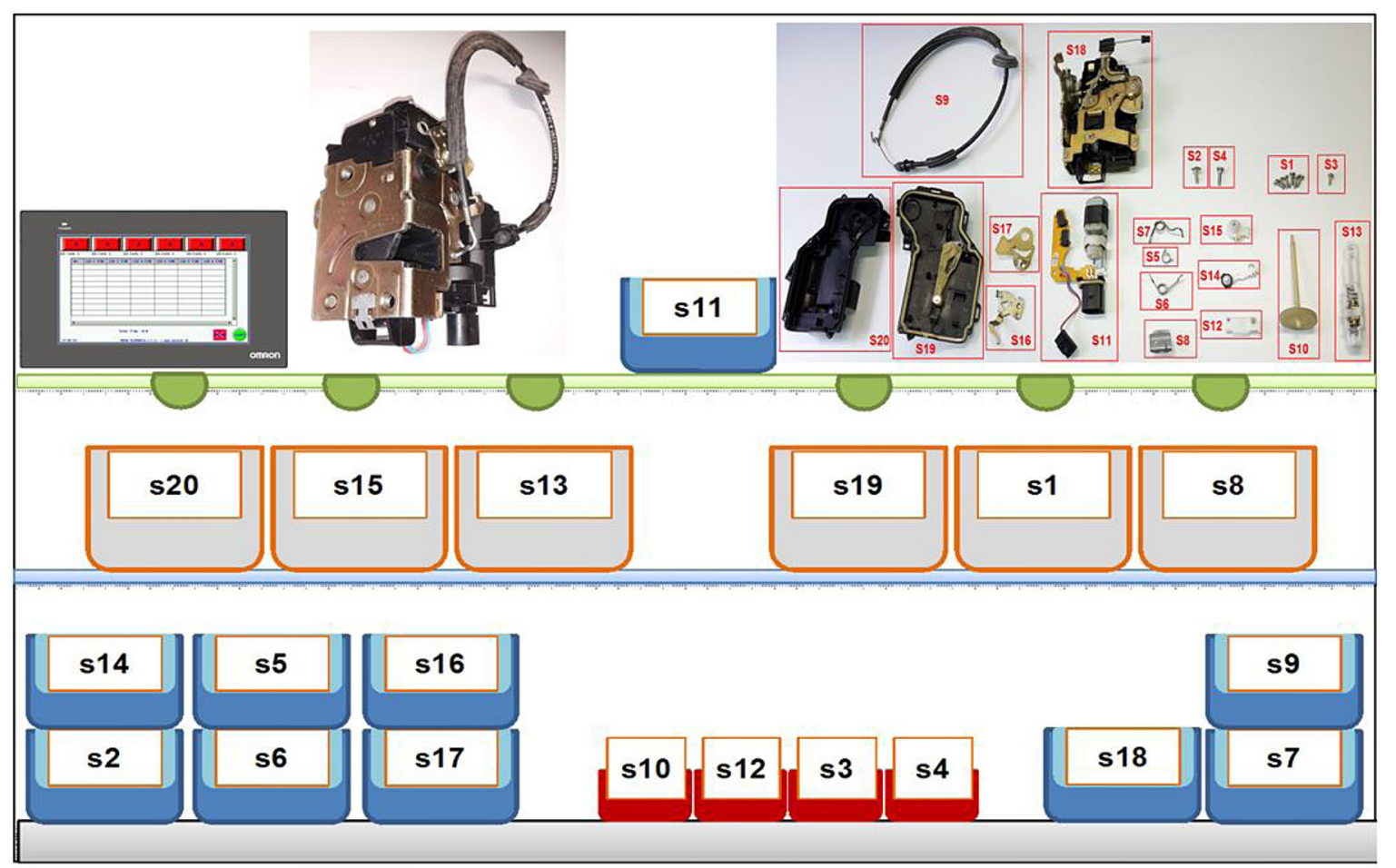

Figure 7. Suggested layout of the workplace

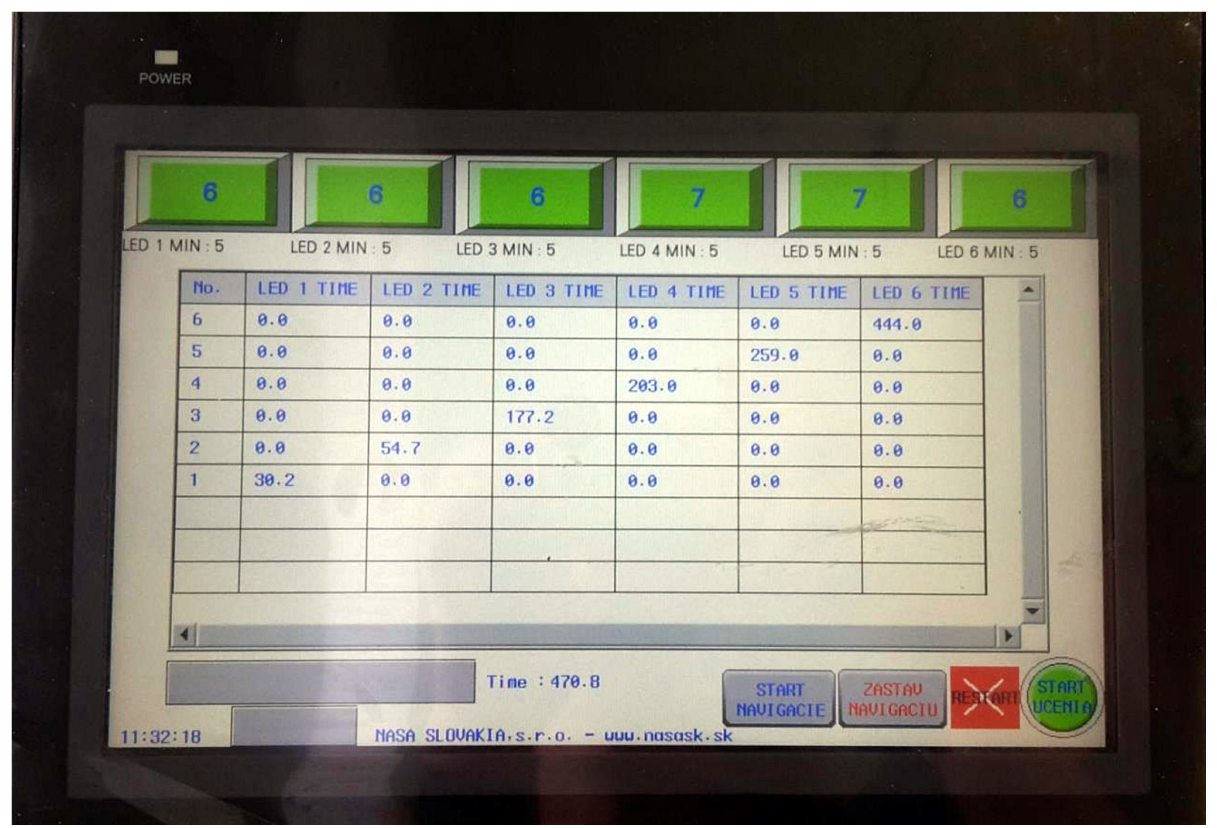

Figure 8 HMI panel screen after product assembly with new program

Table 2 Output from the HMI panel on the USB key of the new program

\begin{tabular}{|c|c|c|c|c|c|c|c|c|}
\hline DATE & TIME & $\mathrm{CH} 0$ & $\mathrm{CH} 1$ & $\mathrm{CH} 2$ & $\mathrm{CH} 3$ & $\mathrm{CH} 4$ & $\mathrm{CH} 5$ & $\mathrm{CH} 6$ \\
\hline $2015-04-27$ & $11: 24: 58: 154$ & 1 & 30.200001 & 0.000000 & 0.000000 & 0.000000 & 0.000000 & 0.000000 \\
\hline $2015-04-27$ & $11: 25: 22: 764$ & 2 & 0.000000 & 54.700001 & 0.000000 & 0.000000 & 0.000000 & 0.000000 \\
\hline $2015-04-27$ & $11: 27: 25: 188$ & 3 & 0.000000 & 0.000000 & 177.199997 & 0.000000 & 0.000000 & 0.000000 \\
\hline $2015-04-27$ & $11: 27: 50: 869$ & 4 & 0.000000 & 0.000000 & 0.000000 & 203.000000 & 0.000000 & 0.000000 \\
\hline $2015-04-27$ & $11: 28: 46: 994$ & 5 & 0.000000 & 0.000000 & 0.000000 & 0.000000 & 259.000000 & 0.000000 \\
\hline $2015-04-27$ & $11: 31: 51: 803$ & 6 & 0.000000 & 0.000000 & 0.000000 & 0.000000 & 0.000000 & 444.000000 \\
\hline
\end{tabular}


Table 3. Modified output file of the new program from the HMI panel

\begin{tabular}{|c|c|c|c|c|c|c|c|c|}
\hline DATE & TIME & No. & $\mathrm{CH} 1$ & $\mathrm{CH} 2$ & $\mathrm{CH} 3$ & $\mathrm{CH} 4$ & $\mathrm{CH} 5$ & $\mathrm{CH} 6$ \\
\hline 27.4 .2015 & $11: 24: 58: 154$ & 1 & 30.2 & 0.0 & 0.0 & 0.0 & 0.0 & 0.0 \\
\hline 27.4 .2015 & $11: 25: 22: 764$ & 2 & 0.0 & 54.7 & 0.0 & 0.0 & 0.0 & 0.0 \\
\hline 27.4 .2015 & $11: 27: 25: 188$ & 3 & 0.0 & 0.0 & 177.2 & 0.0 & 0.0 & 0.0 \\
\hline 27.4 .2015 & $11: 27: 50: 869$ & 4 & 0.0 & 0.0 & 0.0 & 203.0 & 0.0 & 0.0 \\
\hline 27.4 .2015 & $11: 28: 46: 994$ & 5 & 0.0 & 0.0 & 0.0 & 0.0 & 259.0 & 0.0 \\
\hline 27.4 .2015 & $11: 31: 51: 803$ & 6 & 0.0 & 0.0 & 0.0 & 0.0 & 0.0 & 444.0 \\
\hline
\end{tabular}

Benefits of the new program are as follows:

- This is a full-featured Pick to Light system

- The system is fault-tolerant

- Easier analysis of output data as a result of failure to record faulty steps

- Disadvantages of the new program:

- The greatest disadvantage of the program is the ability to learn a sequence consisting of a maximum of nine steps, due to a small PLC memory

- More complex operation, the same sequence of operations must be followed

- It is not possible to run only time measurement without navigation

\section{CONCLUSION}

A new PLC program was created, which was the main goal of the contribution. The instructions on how to use the new program and how to implement the program into the PLC were created. The program was tested on the car door component of a door lock. The test also encountered unexpected problems in the theoretical preparation. The new program is functional, but it also has some drawbacks mainly due to the way the program is written and limited PLC memory. In the future, it would be advisable to try to overwrite the program using text-based text or use functional blocks to save steps and increase the number of steps the system can learn without the need for PLC exchange. Certainly, it would be advisable to add a number of sensors over other trays to get the system closer to the Pick to Light system used to assemble components and products.

In order to compare the outputs of the new and the original program from the HMI panel that were stored on the USB key, it is necessary to adjust the outputs first. Because it is not possible to choose the format of the data that is saved to the key, it would be appropriate to create an application capable of converting the output data. This would save time in comparing results.
The selected component, i.e. the door lock, is not ideal for demonstrating a new program. In order to demonstrate time savings, a more convenient component with fewer individual elements would be ideal. It is assumed that in such a case, the time difference between the original and the new programs would be more obvious.

\section{Acknowledgements}

This work has been supported by the Scientific Grant Agency of the Ministry of Education of the Slovak Republic (VEGA 1/0376/17)

\section{REFERENCES}

1. Daneshjo N., M, Majernik, E, Danishjoo: More Exact Approaches to Modernization and Renewal of the Manufacturing Base. TEM Journal. 6(3), 2017, 445-449, DOI: 10.18421/TEM63-03.

2. Daneshjo N., E. Dudaš Pajerská, M. Klimek, E. Danishjoo: Software Support for Optimizing Layout Solution in Lean Production. TEM Journal. 7(1), 2018, 33-40, DOI: 10.18421/TEM71-05.

3. Dietrich C., N. Daneshjo, M. Danishjoo: Failure prevention in maintenance services and logistics. Modern Machinery Science Journal, June 2017, Prague, Czech Republic,

4. Fabian M., Ižol P., Draganovská D., Tomáš M. Influence of the CAM parameters and selection of end-mill cutter when assessing the resultant surface quality in 3D milling. Applied Mechanics and Materials, 474, 2014, 267-272.

5. Ižol P., Fabian M., Kopas M., Fedorko G. Evaluation of machining strategies for production of free form surfaces using 3-axle milling. Manufacturing Technology, 13(4) 2013, 458-465.

6. Králik M., Jerz V. (2018). The measurement of residual stresses in the surface layers of the materials after machining. Materials Science Forum, 919, 2018, 345-353.

7. Šeminský J. Present trends in designing of technical systems. Applied Mechanics and Materials, 460, 2014, 73-80. 